\title{
APRESENTAÇÃO \\ SOBRE GÊNERO, RAÇA E CONSTRUÇÕES \\ CORPORAIS: ALINHAVANDO CONEXÕES E \\ DESCOSTURANDO DUALIDADES
}

Sonia Maria Giacomini ${ }^{*}$

Olívia Nogueira Hirsch**

*Sonia Giacomini é antropóloga pelo Programa de Pós-graduação em Antropologia Social do Museu Nacional da Universidade Federal do Rio de Janeiro (PPGAS-MN/UFRJ) e socióloga pelo Instituto Universitário de Pesquisas do Rio de Janeiro (IUPERJ), docente e pesquisadora do Programa de Pós-Graduação em Ciências Sociais da Pontifícia Universidade Católica do Rio de Janeiro (PPGCIS/PUC-Rio). Pesquisa gênero, raça, corpo e sexualidade no Brasil, tendo publicado, entre outros livros, Mulher e escrava: uma introdução histórica ao estudo da mulher negra no Brasil (Vozes, 1988), A alma da festa (Editora UFMG; IUPERJ, 2006) e diversos artigos.

** Olivia Hirsch é doutora em Ciências Sociais pela Pontifícia Universidade Católica do Rio de Janeiro (PUC-Rio), onde também atua como docente na área de Antropologia. Pesquisa antropologia da saúde, corpo, gênero e maternidades, e é autora do livro Parto natural, parto humanizado: perspectivas de mulheres de camadas populares e médias, publicado pela editora Fiocruz (2019). 
É notório o interesse (e o aumento em sua quantidade) por pesquisas que vêm discutindo mudanças associadas à implementação de políticas no Brasil que há mais de uma década estão se direcionando para minorias raciais e étnicas, igualdade de gênero e direitos sexuais. Abarcando amplo leque de temas, destacam-se na produção acadêmica contemporânea as contribuições que refletem sobre gênero, raça e sexualidade. O estudo desses temas à luz de novas abordagens tem resultado em aportes que, mais além de aprofundarem discussões acerca de assuntos já consolidados, apontam para a construção de novos temas e objetos.

Ressalta-se também que esses novos olhares e abordagens decorrem, em boa parte, da conexão e da sintonia com as dinâmicas de movimentos sociais, feministas, negros, LGBTQ+, focalizando sobretudo interações entre diferentes maneiras de construção da alteridade, na abordagem conjugada de vários marcadores sociais de diferença que, de maneira combinada, interseccional (CREENSHAW, 2002) ou consubstancial (KERGOAT, 20IO), convivem em modos de pensar, agir e sentir da vida social. Assim, questões que no passado eram comumente tratadas de maneira isolada ou, quando muito, situadas em mera justaposição, passaram a ganhar novo fôlego e a se enriquecer mutuamente através de abordagens teóricas e categorias que enfatizam as diferentes conexões e formas combinadas de opressão - isto é, de marcas e identificações que, combinadas, registram e produzem as diferenças que de maneira simultânea constroem indivíduos e corpos generificados e racial e sexualmente marcados. De formas específicas e combinadas, as experiências individuais e coletivas de negros(as), brancos(as), pardos(as), homens, mulheres, LGBTQ+ e outras, em todas as suas possíveis feições e recombinações, são referências que permitem explorações que ampliam as possibilidades de compreensão das formas de opressão e discriminação que identificam nas sociedades contemporâneas indivíduos e grupos "marcados".

Trata-se de indivíduos e grupos cuja alteridade é hierarquizada, cuja diferença é transmutada em desigualdade, que, como enfatiza boa parte da produção contemporânea, são construídos através de um contraste com sujeitos considerados referência e padrão, e que, justamente por permanecerem subentendidos e onipresentes, representam de maneira eficiente e emblemática o universal: o homem branco heterossexual das camadas sociais superiores. Nesse sentido, a emergência de conceitos e noções como branquitude (ou witheness), assim como masculinidade hegemônica e heterossexualidade, vem suscitando e alimentando a reflexão crítica acerca de significado e valor sociais do privilégio de ser classificado como universal e não marcado em um mundo altamente inigualitário. Isso coloca em pauta a necessidade de construção de alianças nas lutas pelos direitos humanos contra a desigualdade social, em particular contra o sexismo, o racismo e a heteronormatividade. 
Como se combinam diferentes "marcas" de opressão? Essa questão, como se sabe, estava ausente das primeiras formulações da produção sociológica e antropológica sobre gênero que, sobretudo até os anos I970, reivindicavam o papel decisivo do sistema de sexo-gênero (RUBIN, I975) e o da divisão público/privado nas formas de configuração da subordinação das mulheres. Nessas formulações as mulheres apareciam confinadas ao espaço doméstico, ao passo que no espaço investido de poder, o espaço público, estavam os homens. ${ }^{1}$ Donna Haraway, em denso texto em que reúne diferentes teorizações sobre o conceito de gênero (2004), aponta o influente artigo de Sherry Ortner - sugestivamente intitulado "As mulheres estão para a natureza assim como os homens estão para a cultura", publicado em uma coletânea em 1974 - como o texto que condensa a teorização mais recorrente na segunda metade dos anos 1970.

Com efeito, a oposição natureza-cultura, desdobrada como oposição homemmulher, presente na formulação de Ortner, serviu como um marco e teve largo curso no pensamento feminista da época. Embora a universalidade dessa oposição tenha sido recebida pela antropologia de maneira crítica e tenha conduzido essa disciplina a ricas abordagens transculturais de simbolismos de gênero que a contradiziam, tais ideias, "não obstante, persistiram em muitos discursos fora dos círculos antropológicos, como se as posições de meados dos anos 70 fossem uma teoria feminista antropológica permanentemente autorizada e não um nódulo discursivo num momento específico político-histórico disciplinar" (HARAWAY, 2004, p. 237). Concordando com a autora, é preciso destacar que somente em período bem mais recente a universalidade do dualismo natureza-cultura passou a ser mais ampla e profundamente reconsiderada no pensamento feminista.

O que teria contribuído para a revisão dessas oposições e universalidades?

Não seria exagero afirmar que as mais agudas críticas políticas às formulações teóricas feministas universalizantes chegaram através da voz de mulheres que simplesmente não se reconheciam nos enquadramentos que postulavam a distinção natureza-cultura que informa a conhecida proposição do sistema de sexo-gênero proposta por Gayle Rubin (1975). A “domesticação das mulheres” era, nessa formulação, o resultado de um "sistema de relações sociais que transforma a sexualidade biológica em produtos da atividade humana" (RUBIN, I975, p. I59). As fêmeas humanas são um material bruto na produção social de mulheres que ocorre através da troca nos sistemas de parentesco controlados por homens na fundação da cultura humana (RUBIN, 1975). Como se situavam, então, as mulheres racializadas e etnicizadas, sobretudo negras, e/ou as

\footnotetext{
${ }^{1}$ Destaca-se, por sua importância e grande difusão também no Brasil, a coletânea de ROSALDO, M.; LAMPHERE, L. (Eds). Women, culture and society. Palo Alto: Stanford University Press, 1974. Essa coletânea foi traduzida e publicada em português sob o título Mulher, cultura e sociedade. Rio de Janeiro: Paz e Terra, 1979.
} 
mulheres do chamado "terceiro mundo", ou da periferia do capitalismo? Universalizada, a categoria gênero identificava um sujeito do feminismo no qual eram obscurecidas ou secundarizadas todas as outras alteridades, revelando assim forte impregnação etnocêntrica e imperialista dos feminismos europeu e estadunidense.

Dessa maneira, se "a produção social de mulheres" se dá nos marcos da troca no interior dos sistemas de parentesco, como então pensar a posição social das mulheres que se encontram fora dessa instituição do parentesco característica do grupo dominante? Como pensar aquelas cuja posição não decorre do lugar ocupado no próprio sistema de parentesco (RUBIN, I975), mas sim das formas de funcionamento do sistema de parentesco de outro grupo, o grupo dominante? Tanto a posição social quanto o processo de produção dessas "outras" mulheres permaneceram completamente invisibilizados na teoria feminista, justamente por não se encaixarem no enquadramento conceitual proposto. ${ }^{2}$ Fora das configurações em que estavam sendo pensadas as opressões de gênero encontravam-se, no entanto, todas aquelas "outras" mulheres que, circulando, convivendo e, sobretudo, trabalhando dentro e fora do espaço privado feminizado, não se encaixavam no modelo. Mais que isso: o não reconhecimento, ou desconhecimento, de certa maneira autorizava questionar, relativizar ou desqualificar até mesmo sua inclusão na categoria mulher modelar assim constituída.

Uma importante reflexão do feminismo negro, especialmente norte-americano, investiu na produção de teorias sobre os sistemas de diferenças em que raça, sexo, classe, nacionalidade, no presente e no passado, se entrelaçavam (ver DAVIS, 20I6; COLLINS, 2008, entre outras). No Brasil, assim como nos Estados Unidos, ambos países profundamente marcados por um passado escravagista, há que se mencionar uma produção feminista que desde os anos I980 se debruçou sobre a vida das escravas negras, mulatas, mães-pretas, mucamas e quitandeiras (GONZALEZ, I984; CARNEIRO, 2OII; BAIRROS, I995; MAGALHÃES; GIACOMINI, I983; GIACOMINI, I985, I988; e outras). Na atualidade, em que se mantêm e se reproduzem diferenças profundas que segundo Spillers (1987) extrapolaram a abolição formal, existem consequências definitivas até o final do século XX e continuarão a existir até que o racismo - uma instituição fundadora do Novo Mundo - tenha acabado.

Fora dos vínculos e da gramática do parentesco, as mulheres escravas "marcadas" e racializadas foram constituídas como fêmeas. Animalizadas, sexualizadas, era-lhes negada a condição mesma de "mulher", socialmente construída como aquela que é humana, posto que esposa e mãe. Assim destituídas dos atributos aos quais se acede

\footnotetext{
2 “Ain't a woman?", escreveu bell hooks (1981), retomando a frase histórica e questionando ironicamente a não inclusão de mulheres negras em uma formulação em que o sujeito do feminismo é restringido.
} 
através do casamento, essas fêmeas não mulheres não participavam da transmissão de um nome por estarem fora das trocas matrimoniais.

Foi somente quando a sexualidade, a maternidade, o trabalho, o parentesco e a sociabilidade também dessas "outras" passaram a ser incluídos na reflexão feminista e de gênero, que ganhou impulso a formulação de uma teoria crítica da produção de sistemas de diferenças hierárquicas. O entendimento de que não há uma identidade única, pois a experiência de ser mulher não é indissociada de raça, gênero, classe social, orientação sexual, foi certamente uma contribuição relevante do feminismo negro. A grande novidade trazida por essa perspectiva é a de que a partir daí não seria mais possível falar na/da mulher em geral, pois a experiência da opressão da mulher decorre da posição que ocupa em uma matriz de dominação em que raça, gênero e classe social encontram-se conectadas de múltiplas maneiras e em várias combinações. A experiência de ser mulher se dá, portanto, social e historicamente determinada.

No âmbito desse breve comentário a respeito dos aportes que vieram enriquecer a produção sobre gênero, raça e construções corporais nas ciências sociais contemporâneas, não poderia estar ausente a decisiva contribuição trazida pelo pensamento decolonial, sobretudo nos países periféricos. A chamada perspectiva decolonial tem colaborado de maneira ampla e significativa ao oferecer um novo olhar para os temas que aqui nos interessam, ao postular que há corpos, sexualidades, gêneros e raças construídos a partir da colonialidade. Ao identificar na ideia de "raça" um elemento fundante da colonialidade do poder, Quijano (2002) chama a atenção para o fato de que no sistema de poder contemporâneo a "raça" tem lugar central, pois opera como fundamento do padrão universal de classificação social básica e de dominação social.

A própria ideia de "raça" e a classificação social que a tem como base, ambas originadas há mais de 500 anos, contemporânea e articuladamente com o nascimento da América e da Europa, da metrópole e da colônia, do centro e da periferia, da modernidade e do capitalismo, são encaradas por essa corrente de pensamento como "a mais perdurável expressão da dominação colonial e [foram] impostas a toda população do planeta no curso da expansão do colonialismo europeu" (QUIJANO, 2002, s. p., grifo nosso). Desde então, o conceito de "raça" e o sistema de classificação racial que lhe é coessencial têm demonstrado uma enorme vitalidade e uma impressionante longevidade, posto que no padrão atual de poder impregnam todas as dimensões da vida social, consistindo na "mais profunda e eficaz forma de dominação social, material e intersubjetiva, e são, por isso mesmo, a base intersubjetiva mais universal de dominação política dentro do atual padrão de poder" (QUIJANO, 2002, s.p.).

Além da indelével presença da "raça" na colonialidade, as inter-relações entre colonialidade e patriarcado vêm sendo exploradas de maneira bastante fértil e sugestiva 
pela reflexão decolonial, provocando importantes debates sobre a existência ou não de nomenclaturas de gênero nas sociedades tribais e afro-americanas, ${ }^{3}$ sobre o lugar da mulher nessas configurações, e, sobretudo, lançando novas pistas que permitem ampliar a compreensão a respeito da diversidade das relações de gênero e sexualidade que coexistem na contemporaneidade.

Destaca-se nessa produção feminista decolonial a contribuição de Rita Segato, antropóloga que confere à reflexão sobre o gênero um real estatuto teórico e epistêmico, ao examiná-lo como uma categoria que ilumina as transformações impostas às comunidades capturadas e submetidas à nova ordem colonial/moderna. Segato problematiza as maneiras pelas quais o colonialismo modificou historicamente as relações de gênero dos povos submetidos à colonização e examina os resultados dessas transformações na atualidade. A colonialidade é "uma matriz que organiza hierarquicamente o mundo de forma estável" (SEGATO, 2OI2, p. II3), e que apresenta uma forma interna: "uma história que instala uma episteme da colonialidade do poder e da raça como classificadores [...] e também uma história das relações de gênero dentro do cristal do patriarcado" (p. II3). Essas histórias "respondem à expansão dos tentáculos do Estado modernizador no interior das nações [...] desarticulando, rasgando o tecido comunitário, levando o caos e introduzindo uma profunda desordem em todas as estruturas que existem e no próprio cosmos" (p. II3).

Um dos efeitos desse processo, o qual provoca um desordenamento das estruturas anteriores do "mundo-aldeia" (pré-intrusão da colonial/modernidade), seria o "agravamento e a intensificação das hierarquias que formavam parte da ordem comunitária pré-intrusão", isto é, que "exacerbaram e tornaram perversas e muito mais autoritárias as hierarquias que já continham em seu interior - que são basicamente as de status, como casta e gênero" (SEGATO, 2OI2, p. II4).

De acordo com Segato (2012), a infiltração das relações de gênero da ordem colonial moderna nas relações de gênero no "mundo-aldeia" teria redundado em uma espécie de "entroncamento de patriarcados", de que resultaram profundas alterações na organização das relações de gênero no "mundo-aldeia". No mundo-aldeia haveria estruturas de gênero reconhecíveis e, à primeira vista, assimiláveis ao que se denominam relações de gênero na modernidade (p. II7), envolvendo hierarquias de prestígio entre a masculinidade e a feminilidade. Mas haveria uma importante diferença, pois no mundo-aldeia "são mais frequentes as aberturas ao trânsito e à circulação entre essas posições que se encontram interditas em seu equivalente moderno ocidental" (p. II7). A heteronormatividade ou a transgenerificação no contexto do mundo-aldeia, ao contrário do que ocorre na

\footnotetext{
${ }^{3}$ Ver entre autores para quem o gênero inexiste no mundo pré-colonial (LUGONES, 2007).
} 
modernidade, faz parte de linguagens e de práticas nada incomuns ao mundo préintrusão. Segato (2012) chama a atenção para a presença, em uma série de povos indígenas latino-americanos e norte-americanos, além de todos os grupos religiosos afro-americanos, de "linguagens" e "práticas transgenéricas estabilizadas, casamentos entre pessoas que o Ocidente entende como do mesmo sexo e outras transitividades de gênero bloqueadas pelo sistema de gênero absolutamente engessado da colonial/modernidade" (p. II7).

No que concerne à masculinidade no mundo-aldeia pré-intrusão, esta constituía status somente adquirido através de provações, inclusive o enfrentamento da morte; o sujeito deve conduzir-se continuamente de modo a fazer prova de habilidades e resistência sob os olhares avaliativos de seus pares, "para poder exibir o pacote de seis potências - sexual, bélica, política, intelectual, econômica e moral - que lhe permitirá ser reconhecido e qualificado como sujeito masculino" (p. II8).

Ao intrudir o gênero da aldeia, a modernidade/colonialidade

modifica-o perigosamente, intervém na estrutura de relações da aldeia, apreende-as e as reorganiza a partir de dentro, mantendo a aparência de continuidade, mas transformando os sentidos ao introduzir uma ordem agora regida por normas diferentes [...] as nomenclaturas permanecem, mas são reinterpretadas à luz de uma nova ordem moderna. Esse cruzamento é realmente fatal, porque um idioma que era hierárquico em contato com o discurso igualitário da modernidade transforma-se em uma ordem ultra-hierárquica. (SEGATO, 2OI2, p. II8)

Dessa maneira, ao chamar a atenção para o fato de que no mundo "pré-intrusão" colonial o gênero é regulado como "uma dualidade hierárquica", isto é, "na qual ambos os termos que a compõem, apesar da sua desigualdade, têm plenitude ontológica e política" (p. I22), Segato (2012) evidencia que, por contraste, no mundo da modernidade não há dualidade, mas binarismo de gênero. Ao passo que na dualidade a relação entre os gêneros é de complementaridade, o mesmo não ocorre no binarismo, uma vez que

a relação binária é suplementar, um termo suplementa o outro, e não o complementa. Quando um desses termos se torna "universal", quer dizer, de representatividade geral, o que era hierarquia se transforma em abismo, e o segundo termo se transforma em resíduo, essa é a estrutura binária, diferente da dual. (SEGATO, 2OI2, p. I22)

Ainda que o recurso à expressão "patriarcado de baixa intensidade" gere certa ambiguidade, ao sugerir que se estaria diante de graus de intensidade de um mesmo e único fenômeno, e não de sistemas de relações diferenciados, a comparação entre o lugar e as representações da mulher, da feminilidade, do homem e da masculinidade no mundo- 
aldeia e na modernidade oferece desafiadores contrapontos a ser considerados na reflexão sobre a colonialidade das relações de gênero.

Suplemento ou complemento, dualismo e binarismo convivem e coexistem na atualidade? São questões que surgem do contato com as reflexões trazidas no bojo do pensamento decolonial. Desse modo, pensar as relações de gênero a partir da perspectiva crítica da decolonialidade abre caminho para refletir não apenas sobre as relações de gênero e suas formas específicas na contemporaneidade, mas também sobre as relações entre as diferentes formas que coexistem e nas maneiras como são explicadas essas mesmas diferenças.

Outra chave que tem marcado presença de maneira relativamente constante nos estudos atuais é a da exploração da dimensão corporal dos atores sociais, dimensão esta que tem se mostrado particularmente fecunda ao rever a abordagem biologizante ou biomédica do corpo, quase hegemônica no tratamento do corpo e da corporeidade nas ciências sociais. Como já observou Le Breton (2OII), pensar criticamente o lugar do corpo nas sociedades contemporâneas requer a revisão de algo profundamente entranhado na cultura ocidental. Tentar devolver ao corpo sua dimensão social e cultural e pensá-lo não como um alter ego, um outro, mas antes como confundido com o sujeito, exige a reflexão sobre os gêneros, as raças, as gerações, os grupos etários e as classes, compreendendo os corpos e os investimentos corporais dos sujeitos não somente como "naturais" ou construções sociais que incidem sobre os sujeitos e os "marcam", mas também como parte da agência dos sujeitos incidindo sobre seus corpos e na relação com os outros. Nesse sentido, a proposta de refletir sobre as formas de opressão que imprimem nos corpos o gênero, a raça, a sexualidade, a classe, a geração etc., e que produzem hierarquias combinadas e recombinadas, encontra na revisão crítica de uma concepção biomédica do corpo, que o apresenta como uma máquina, massa de carne, evidência, naturalizado, um fértil ponto de partida para entender e captar formas de agência dos sujeitos em contextos no quais são criados novos sentidos e identificações.

Em um empreendimento crítico do estudo da corporalidade no qual são abertos espaços para a análise dos sentidos e nexos das "diferenças" inscritas nos corpos, tem certamente lugar de destaque o exame de sociedades e grupos sociais em que não se verifica uma separação binária entre homens e mulheres e seus corpos, característica e recorrente no mundo ocidental. A esse respeito merece menção o registro do etnólogo e pastor Maurice Leenhardt, que conviveu com os canaque por um longo período - entre I920 e I930. Em uma das conversas travadas com o chefe daquele povo da Melanésia, Oceania, Leenhardt comentou que o longo convívio com os missionários ocidentais havia ensinado aos canaque que eles tinham uma alma. Ao que respondeu o chefe: "Não, que temos uma alma nós já sabíamos, vocês nos ensinaram que nós temos um corpo" 
(LEENHARDT, I97I, p. 263). ${ }^{4}$ De fato, como observou na continuidade o próprio Leenhardt, os canaque não tinham uma palavra para "corpo" antes da chegada dos ocidentais. E teria sido juntamente com a incorporação da noção de que eles tinham um corpo que se abriu a possibilidade de individuação, de fixação de limites que coincidem com os limites do corpo e do "eu", o que tornou possível o afrouxamento da rede de relações da sociedade tradicional melanésia, na qual a pessoa é sempre um lugar relacional em uma totalidade social (LEENHARDT, I97I).

Se a noção de ter um corpo não é universal e esta noção abre, na modernidade, a possibilidade de individuação, surge outra questão: como o processo de individuação e fragmentação percorreu seu longo caminho nas sociedades modernas, ocidentais, centrais? De que modo foi o corpo instaurado lócus de marcação das diferenças, através de que caminhos e dispositivos o corpo teria sido como que convocado para falar cada vez mais a "verdade" do sujeito (BOURDIEU, 1977)? Ora, falar de marcação é falar de gênero, raça e sexualidade, que são as que nos interessam aqui mais de perto, e que encontram na formulação de sociedade disciplinar de Foucault um amplo campo de reflexões em que podem ser percebidas como integrando os dispositivos de poder que constroem os sujeitos modernos e que, dessa maneira, participam dos jogos de poder que marcam a contemporaneidade.

Ao problematizar a impregnação genérica da oposição binária corpo e espírito nas sociedades ocidentais, Le Breton (2OII) chama a atenção para o fato de que "as concepções do corpo são tributárias das concepções da pessoa" (p. 8). Assim, nas sociedades tradicionais, diferentemente do que ocorre nas sociedades ocidentais modernas, o corpo não se distingue da pessoa, ou seja, os mesmos materiais que compõem a espessura do ser humano encontram-se na composição do cosmos, na natureza, o que certamente não oferece referentes de individuação, mas de pertencimento ao todo, ao cosmos.

Este dossiê reúne trabalhos selecionados dentre os apresentados no ST I25 Intersecções, Transformações e Conexões nas Pesquisas sobre Gênero, Raça e Corporalidade, coordenado por Sonia Maria Giacomini e Angela Figueiredo, no âmbito do I3th Women's World \& Fazendo Gênero II - Transformações, Conexões, Deslocamentos, realizado em Florianópolis, de 30 de julho a 4 de agosto de 20I7. A expectativa é de que tragam uma contribuição original ao debate e à reflexão sumariamente expostos anteriormente nesta apresentação.

O artigo de Joyce Gonçalves Restier da Costa Souza, "Corpos em busca do belo: as mulheres negras e a beleza na eugenia da Era Vargas", convida a discutir como a dualidade

\footnotetext{
${ }^{4}$ Essa famosa passagem de Leenhardt encontra-se em uma publicação de 1944 e tem sido citada por estudiosos de diferentes gerações, ver Laplantine (1991), Csordas (2009) e Maluf (2002). A reflexão de Leenhardt sobre os melanésios, como observou Thomas Csordas, tem servido de inspiração e chegou a antecipar a reflexão antropológica contemporânea sobre diversos temas, entre eles sobre o corpo e a corporalidade.
} 
corpo-espírito se atualiza e se hierarquiza nas oposições homem-mulher, branco-negro, razão-emoção. Ao analisar como se situavam as mulheres negras em meio ao ideal de beleza vigente entre os anos 1930 e 1945, período de disseminação da teoria do branqueamento, a autora chama a atenção para as dinâmicas e estratégias adotadas pela comunidade negra com o intuito de promover a valorização dos atributos físicos dessas mulheres. Destacam-se nesse cenário os esforços empreendidos pela Frente Negra Brasileira (FNB) e, principalmente, pelo Teatro Experimental do Negro (TEN), fundado em I940, no Rio de Janeiro. Excluídas dos grandes concursos de rainhas e misses por não se ajustarem aos padrões de beleza da sociedade hegemônica, as mulheres negras encontraram nos eventos promovidos pelo TEN um espaço onde suas qualidades físicas passaram a ser ressignificadas e valorizadas.

No artigo "Rainhas do clube e musas do samba-rock: raça e gênero na sociabilidade negra", Karina Almeida de Sousa também se detém sobre organizações negras e seus respectivos concursos de beleza, a partir de pesquisa sobre clubes sociais negros e bailes da capital e do interior do estado de São Paulo. No passado, teria havido uma tentativa de os membros dos clubes se distanciarem dos estigmas que recaíam sobre a população negra, engendrando uma preocupação com a moralidade e com a reprodução de padrões de classe. A escolha das rainhas dos clubes sintetizava esse esforço de afirmação de uma mobilidade social familiar, e aquelas eleitas para representar a instituição eram as que encarnavam a representação de um feminino gentil, dócil, educado, sensível e servil, o mesmo esperado das mulheres brancas de camadas médias. Nos tempos atuais, destaca a autora, ainda pode ser observada certa moralidade, mas a inclusão do samba-rock como dança de salão, bem como sua difusão em escolas de dança, tem propiciado mudanças no que se refere ao papel e à representatividade das mulheres negras nesses espaços.

Os dois artigos seguintes direcionam o foco para a literatura. Em "Literatura e interseccionalidade: A resposta, de Kathryn Stockett, e os lugares de fala subalternos", Ana Paula Moritz analisa o livro que serviu de base à elaboração do filme Histórias cruzadas, sucesso de bilheteria em 20II. O romance, publicado em 2009, trata das relações entre patroas brancas e empregadas domésticas negras no estado do Mississipi, sul dos Estados Unidos, na década de I960. Em diálogo com as reflexões acerca da escrita etnográfica, da teoria literária, dos estudos pós-coloniais e da teoria feminista, Moritz denuncia a visão romanceada que Stockett apresenta dessas relações, bem como a exclusão e o silenciamento das vozes marginalizadas, isto é, das personagens negras e pobres. A autora também contrapõe a repercussão de $A$ resposta à pouca visibilidade alcançada por pesquisas de cunho sociológico feitas por mulheres negras e que também descrevem essa realidade.

Voltando-se para a América Latina, o artigo "Discursos sobre a democracia racial em Cuba e no Brasil: tramas de gênero, raça e sexualidade na literatura (1933-1978)", de Giselle 
Cristina dos Anjos Santos, compara as representações presentes nas obras Écue-Yamba-Ó (1933), do escritor cubano Alejo Carpentier; e Gabriela, cravo e canela (I958), de Jorge Amado. A autora discute o alinhamento de ambos os escritores a um discurso positivo sobre o fenômeno da mestiçagem, ignorando os conflitos e as violências que historicamente permearam as relações entre brancos e negros nesses países. A figura da mulata ganhou destaque, segundo a argumentação da autora, por ser mais facilmente aceita do que a da negra, considerada inferior. A aparente positivação da mestiçagem e, em consequência, da mulata, se realiza, porém, através de sua hipersexualização e objetificação. Em consequência, tanto Carpentier quanto Amado teriam reforçado esses estereótipos, e historicamente contribuíram para consolidar o imaginário acerca da "mulata" como símbolo das mulheres cubanas e brasileiras.

No artigo seguinte, "Experiências de mulheres negras da favela de Heliópolis (SP) com a violência e suas estratégias de enfrentamento", Alessandro de Oliveira dos Santos, Jackeline Aparecida Ferreira Romio, Christen Anne Smith e Flávia de Paiva Alves da Silva, apresentam resultados de uma pesquisa qualitativa sobre como mulheres negras moradoras de Heliópolis, uma das maiores favelas de São Paulo, compreendem e sentem a violência, seja ela física ou simbólica - como é o caso daquela derivada do racismo. As narrativas indicam que as experiências com a violência atravessam suas vivências familiares, escolares, conjugais e de trabalho e, para seu enfrentamento, contam com um suporte social e religioso, para além de adotar estratégias individuais, como a busca de informações sobre seus direitos.

Por fim, o último artigo, "A importância da política de cotas para o avanço dos estudos de gênero a partir de perspectivas decoloniais no Brasil", de Amanda Alves da Silva e Janja Araújo, direciona o foco ao ambiente universitário. Tomando como ponto de partida os dados sobre a produção discente desenvolvida no âmbito do Programa de Pós-graduação em Estudos Interdisciplinares sobre Mulheres, Gênero e Feminismos (PPGNEIM), da Universidade Federal da Bahia (UFBA), as autoras constatam ter havido um aumento dos estudos que focalizam os feminismos pós-coloniais e decoloniais no Brasil, dentre eles o feminismo negro, e procuram avaliar em que medida isso seria reflexo das políticas de reserva de cotas raciais. Para as autoras, a Lei $\mathrm{n}^{\circ}$ I2.7II, sancionada em 2012 e que ficou conhecida como Lei de Cotas, promoveu a inserção de novos sujeitos(as), o que vem transformando a universidade em um campo de disputa e embate político, bem como um espaço de resistência, o que se reflete na busca por novas epistemologias e perspectivas. 


\section{Referências}

BAIRROS, L. Nossos feminismos revisitados. Estudos Feministas, ano 3, p. 458-463, 2음 semestre 1995 .

BASTIDE, R. La notion de personne en Afrique noire. Paris: CNRS, I98I. p. 33-43.

BOURDIEU, P. Remarques provisoires sur la perception sociale du corps. Actes de la Recherche en Sciences Sociales, n. I4, p. 5I-54, abr. 1977.

CARNEIRO, S. Racismo, sexismo e desigualdade no Brasil. São Paulo: Selo Negro, 20 II.

COLLINS, P. H. Black feminist thought: knowledge, consciousness and the politics of empowerment. New York: Routledge, 2008.

CREENSHAW, K. Documento para o encontro de especialistas em aspectos da discriminação racial relativa ao gênero. Estudos Feministas, ano IO, p. I7I-I88, I- semestre 2002.

CSORDAS, T.J. Corpo/significado/cura. Porto Alegre: Editora da UFRGS, 2009.

DAVIS, A. Mulheres, raça e classe. São Paulo: Boitempo, 2016.

GIACOMINI, S. M. A conversão da mulher em mãe: uma leitura do "A mãi de família”. Revista Brasileira de Estudos Populacionais. Campinas, v. 2, n. 2, p. 7I-98, jul./dez. 1985.

GIACOMINI, S. M. Mulher e escrava. Uma introdução histórica ao estudo da mulher negra no Brasil. Petrópolis: Vozes, 1988.

GONZALEZ, L. Racismo e sexismo na cultura brasileira. Revista Ciências Sociais Hoje, Anpocs, p. 223-244, 1984 .

HARAWAY, D. Gênero para um dicionário marxista. Cadernos Pagu, n. 22, p. 20I-246, 2004.

HOOKS, b. Ain't a woman? Black women and feminism. Boston: South End Press, I98I.

KERGOAT, D. Dinâmica e consubstancialidade das relações sociais. Novos Estudos, Cebrap, n. 86, p. 93-IO3, mar. 2010.

LAPLANTINE, F. Aprender antropologia. São Paulo: Brasiliense, I99I.

LE BRETON, D. Antropologia do corpo e modernidade. Petrópolis: Vozes, $201 \mathrm{I}$.

LEENHARDT, M. Do kamo. La personne et le mythe dans le monde mélanésien. Paris: Gallimard, I97I.

LUGONES, M. Heterossexualism and the colonial modern gender system. Hypathia, v. 22, n. I, p. I86-209, 2007.

MAGALHÃES, E. H. C.; GIACOMINI, S. M. A escrava ama-de-leite: anjo ou demônio? In: BARROSO, C.; COSTA, A. O. (Orgs.). Mulher, mulheres. São Paulo: Cortez; Fundação Carlos Chagas, 1983. p. 73-88.

MALUF, S. W. Corporalidade e Desejo. Revista de Estudos Feministas, v. IO, n. I, 2002. 
QUIJANO, A. Colonialidade, poder, globalização e democracia. Novos Rumos, v. 4, ano I7, n. 37, 2002.

RUBIN, G. The traffic in women: notes on the "political economy" of sex. In: REITER, R. R. (Ed.). Toward an anthropology of women. Monthly Review Press, p. 157-210, 1975.

SEGATO, R. L. Gênero e colonialidade: em busca de chaves de leitura e de um vocabulário estratégico descolonial. e-cadernos ces, v. I8, Epistemologias feministas: ao encontro da crítica radical, p. IO5-I3I, 2012.

SEGATO, R. L. Inventando a natureza. Família, sexo e gênero no Xangô do Recife. In:

Santos e daimones. O politeísmo afro-brasileiro e a tradição arquetipal. Brasília: Editora UnB, I995. p. II-54.

SPILLERS, H. J. Mama's baby, papa's maybe: an american grammar book. Diacritics, v. I7, n. 2, Culture and Countermemory: The "American" Connection, p. 64-8I, summer, 1987. 